\title{
GOVERNANÇA ULTRAJADA. BRASIL: UMA ROTA DE PERIGO
}

Matusalém Gonçalves Pimenta

Doutorando em Direito Ambiental Internacional pela Universidade Católica de Santos, orientado pela coautora. Mestre em Direito Internacional. Professor convidado de Direito Marítimo da Universidade do Estado do Rio de Janeiro. Autor das obras: Responsabilidade Civil do Prático e Processo Marítimo. Formalidades e Tramitação. Bolsista CAPES.

\section{Eliane Maria Octaviano Martins}

Doutora em Direito pela Universidade de São Paulo. Mestre em Direito pela Universidade Paulista Júlio de Mesquita. Professora do Programa de Doutorado e Mestrado da Universidade Católica de Santos. Presidente da Câmara Arbitral Marítima do Rio de Janeiro. Autora da obra (em três volumes) Curso de Direito Marítimo.

\section{Resumo}

Este artigo tem como objetivo verificar os riscos assumidos pelo Brasil pelo não cumprimento de uma Resolução Internacional. O método de pesquisa escolhido foi o sistêmico/comparativo. A Organização Marítima Internacional (IMO), no âmbito da praticagem, adotou a Resolução A-960 (23), assumindo a postura de governança global. Houve por bem a estes pesquisadores extrair dessa carta internacional cinco princípios fundamentais. Constatou-se que esses princípios são alvos da preocupação da quase totalidade dos países-membros que, ao observá-los, assumem uma atitude de boa governança. Este trabalho coteja os padróes estabelecidos na resolução sub studio com o atual modelo de praticagem brasileiro, apontando para a violação de alguns desses princípios. Correlaciona, ainda, a transgressão aos preceitos fundamentais com três grandes acidentes marítimos que, infelizmente, escreveram uma história da qual a humanidade não tem de se orgulhar: Exxon Valdez, Sea Empress e Costa Concordia. Por fim, conclui-se que, ao vilipendiar os paradigmas internacionais estabelecidos pela IMO, o Brasil coloca em risco, de forma absolutamente inaceitável, o meio ambiente marinho, a segurança da navegação e a vida humana no mar.

\section{Palavras-chave}

Governança global; Praticagem; Resolução; Paradigmas. 


\section{Abstract}

This article aims to determine the risks taken by Brazil for not fulfilling an International Resolution. The research method chosen was the systemic / comparative. In regard to Pilotage, the International Maritime Organization (IMO) adopted the A-960 (23) Resolution, and has upheld it ever since towards a global governance, approach and positioning. The authors of this article have chosen to focus in five fundamental principles, extracted from the Resolution. It has been established that these principles remain paramount to almost all member countries, and, whenever they choose to uphold them, all undertake a standpoint of good governance. This work initially analyses and compares the sub studio Resolution standards towards the present brazilian pilotage model. Moreover, it identifies some discrepancies that lead to non-compliances. Furthermore, it correlates the violation of fundamental principles to three massive maritime accidents that mankind shall not be proud of, i.e. Exxon Valdez, Sea Empress and Costa Concordia. Lastly, final conclusion is that, whenever the international IMO standards are disregarded by Brazilian Authorities, they endanger - most unacceptably - the maritime environment, the safety of navigation, and of human life at sea.

\section{Key words}

Global governance; Pilotage; Resolution; Standards.

\section{Introdução}

Este artigo pretende apresentar a regulação técnica do serviço de praticagem, no âmbito do Direito Internacional, tendo como fundamento principal a Resolução A-960 (23) da Organização Marítima Internacional - IMO. Ao final, procurar-se-á comparar esse paradigma internacional com a atual regulação brasileira, exercida pela Autoridade Marítima, registrando-se as discrepâncias e os perigos a estas inerentes.

Adotou-se o método de abordagem sistêmico, não se pretendendo discutir a validade ou a eficácia do que a IMO considerou e recomendou como sistema seguro de praticagem, vez que essas recomendaçóes foram corroboradas por 171 países. Nesse passo, a metodologia de procedimento escolhida foi a comparativa, caracterizada pelo cotejo do sistema recomendado e o atualmente praticado pelo Brasil.

O trabalho demonstra a cristalina intenção daquela organização internacional de, sem interferir na soberania de cada Estado, influenciar e incentivar os países-membros a regular seus sistemas de praticagem, sob a égide de princípios que possam garantir a segurança da navegação, a salvaguarda da vida humana no mar e a proteção do meio ambiente. No primeiro item, são apresentadas as razóes para uma necessária regulação técnica de âmbito internacional. 
No item seguinte, são analisados os princípios fundamentais da praticagem, extraídos do texto da resolução pesquisada. A violação a esses princípios, ocorrida em alguns países antes e depois da Resolução, é ilustrada por meio de relatos dos grandes acidentes marítimos que marcaram a história da navegação.

Demonstra-se, ainda, que o atual sistema de praticagem, adotado pelo Brasil, encontra-se em desalinho com alguns desses princípios, levando o país aos mesmos riscos indesejáveis que geraram aqueles desastres ecológicos, sendo que um deles, além dos danos ambientais, ceifou algumas preciosas vidas.

O item terceiro cuida de explicar porque a posição assumida pelo Brasil representa um desrespeito à governança global e um desperdício de dinheiro público. Procura esclarecer o paradoxo, caracterizado pelo investimento para exercer uma política pública de liderança internacional junto à IMO, na área da segurança da navegação, conjugado, inexplicavelmente, com a rejeição das decisões e recomendações da própria Organização.

Nas consideraçôes finais, alerta-se para o perigo do intervencionismo brasileiro, em detrimento da técnica necessária, colocando em risco os bens protegidos pelo sistema de praticagem. Ao final, sugere-se uma possível transformação da Resolução em Convenção, com o fito de se ter maior poder de coerção sobre os países relutantes.

Como referencial teórico, estes articulistas apoiaram-se em doutrinadores de escol nas áreas do direito internacional (Quoc Dinh e Mario Giovanoli), da teoria geral do direito (Norberto Bobbio), e na esfera da sociologia e da governança global (Alcindo Gonçalves).

\section{Razões para Regulação Técnica da Praticagem}

A princípio, faze-se necessária uma digressão para explicar a razão da existência de uma regulação técnica da profissão do prático, para, ao depois, entender-se as motivaçóes para uma governança no âmbito internacional.

O prático é um especialista, com conhecimento específico das peculiaridades locais: marés, ventos reinantes, correntes marítimas e seus reflexos nas águas interiores, profundidades, perigos submersos, intensidade do tráfego e outras particularidades que tais. Assim, o comandante, responsável pela condução e segurança de seu navio, cruza mares e oceanos, muitas vezes durante dias, mas, a todo porto que chega, toma dali um expert-o prático - que lhe empresta seus conhecimentos técnicos e particularizados daquela região.

No passado, máxime no mais pretérito, a figura do prático interessava tão somente ao comandante, preocupado naturalmente com a segurança do seu navio, tripulação e carga. Nos dias atuais, há uma mudança de foco que desloca a preocupação privada para a esfera do Estado. 
Como representante do interesse público a bordo, o prático tem no seu atuar o dever de proteger direitos difusos, na seguinte ordem de prioridade: as vidas insertas na aventura marítima, o meio ambiente marinho, a segurança da navegação, a manutenção do tráfego local, o patrimônio público e o privado. Note-se que, não por acaso, listou-se por último o que era mais importante no passado. Explica-se.

Tendo em mente essa escala axiológica, cabe ao prático, como gerenciador de riscos e em situação de conflito de interesses, avaliar, caso a caso, e decidir pela realização ou não de certa manobra ou navegação. Na hipótese de colidência de interesses, em respeito aos princípios gerais do Direito, deve prevalecer decisão que proteja o bem maior.

Como exemplo corriqueiro, tem-se o interesse privado do armador de manobrar seu navio no menor tempo possível, utilizando o calado ${ }^{1}$ máximo estabelecido para o porto. Pretensão legítima que só deve ser negada quando da necessidade de conjugar-se o calado com determinadas condiçóes especiais de maré, se igualmente estas forem estabelecidas pela Autoridade Portuária.

Nessa hipótese, a movimentação do navio deve ser realizada não no tempo desejado pelo armador, mas quando houver água suficiente sob a quilha que permita uma operação segura, em obediência ao dever de proteção do bem maior. Uma manobra executada fora de hora normalmente leva ao encalhe que, dependendo do local do acidente, pode agravar-se, interrompendo o tráfego de outras embarcaçóes, se não causar dano maior.

Infelizmente, essa prática milenar, que torna compulsória a presença de um representante do Estado a bordo, não foi ainda aproveitada em outros setores, como o da aviação civil, por exemplo. Permita-se o paralelo, mutatis mutandis, tão só no campo das ideias. Prossegue-se.

Ainda permanece na mente de todos os brasileiros o acidente com o avião (Airbus A-320 - prefixo PR-MBK), de propriedade da companhia TAM, ocorrido em 17 de julho de 2007. Consoante amplamente divulgado pelos jornais, a aeronave saiu de Porto Alegre com destino a São Paulo - Aeroporto de Congonhas. Ao posar, o avião ultrapassou os limites da pista, colidindo, em infeliz coincidência, com o prédio da TAM EXPRESS. Morreram 199 pessoas: 187 estavam a bordo e outras 12 no solo.

Como principais causas do acidente foram apontadas: a desativação do reversor do motor direito da aeronave, o mau tempo na hora do pouso e a reforma irregular da pista, que foi entregue com deficiência de ranhuras auxiliares da frenagem. Todas essas informaçôes eram de conhecimento do comandante do avião.

1 Calado é uma expressão náutica para identificar a parte do navio que fica submersa, que vai da linha d'água até a quilha, que, por sua vez, é a parte extrema inferior do navio. Os calados podem ser medidos em metros ou em pés. Os portos possuem calados máximos de operação em razão das diversas profundidades locais, devendo haver uma folga abaixo da quilha que permita a movimentaçáo segura do navio. 
Em homenagem ao debate construtivo, o caso merece comparação com a atividade que se analisa e reflexão responsável. O comandante sabia da deficiência da aeronave, em razão da desativação do reversor do motor direito. Sabia das condiçóes meteorológicas que alertavam para chuva no momento do pouso e sabia também que a reforma da pista de Congonhas não tinha sido satisfatória. A conjugação desses fatores apontava para uma decisão de não decolar de Porto Alegre e para a realização de reparos na aeronave.

Obviamente que o comandante estava sendo pressionado para voar naquelas condiçôes, de modo a atender aos interesses dos proprietários da empresa aérea. $\mathrm{O}$ não atendimento às pressóes poderia implicar na perda do emprego. $\mathrm{O}$ mesmo resultaria se o comandante, cumprindo seu dever de transparência para com os passageiros, alertasse sobre as restriçôes que enfrentavam.

Certo é que ninguém ficaria a bordo, se sabedores fossem os passageiros dos riscos daquela operação. Lamentavelmente, prevaleceu o interesse privado, em detrimento do bem maior a ser protegido: as vidas a bordo e no solo.

Apenas como exercício comparativo, poder-se-ia imaginar, não exatamente um prático aéreo, mas, um piloto náo tripulante; um representante do interesse público que fizesse um check list antes da decolagem. Nessa condição, de não subordinado aos proprietários da aeronave, teria esse representante poderes para impedir o voo, em razão do conjunto de fatores que apontava para um possível acidente. Com toda certeza, a sociedade e os usuários desse meio de transporte estariam mais protegidos.

Volta-se aos trilhos da praticagem, para dizer que a partir da consciência do dever de proteção de direitos difusos, razão da necessidade de regulação técnica padronizada no âmbito internacional, a maioria dos países passou a adotar, como medida de boa governança, o trabalho liderado pela Organização Marítima Internacional.

Por indicação de seu Comitê de Segurança Marítima e por meio da Resolução A-960 (23), a IMO adotou uma série de recomendaçóes aos países-membros, em ato de clareza meridiana, de vontade política e de governança global, na tentativa de padronizar os serviços de praticagem em todo o mundo.

$\mathrm{Na}$ mesma sintonia e propósito, houve por bem a estes autores, extrair dessas recomendaçôes os princípios reguladores fundamentais, nelas insertos, com anelo de estabelecer uma nomenclatura que facilite a compreensão das recomendaçóes da IMO nessa Resolução.

\section{Princípios Fundamentais na Resolução A-960 (23)}

O conceito de princípio é extremamente amplo e a matéria admite uma gama interminável de hermenêuticas e exegeses múltiplas que não interessam ao objetivo deste 
artigo. Contudo, não há como compreender uma instituição, uma empresa, um país ou uma profissão, sem conhecer seus princípios fundamentais.

Os princípios que regem uma nação, normalmente, são emoldurados na sua Constituição. Nesse passo, pode-se afirmar, por exemplo, que o Brasil é regido por uma série de princípios, sendo os fundamentais aqueles esculpidos no artigo primeiro da Carta Política: princípio da dignidade da pessoa humana, dos valores sociais do trabalho, da livre iniciativa, entre outros.

No mundo jurídico, a compreensão dos princípios é de fundamental importância, podendo fazer, até mesmo, distinção entre profissionais do mesmo ramo. Para Carlos Sundfeld (1992), conhecer princípios e saber usá-los diferencia o jurista do mero conhecedor de textos legais.

No âmbito das profissóes, os princípios são os pilares que permitem a real compreensão da necessidade e dos valores de determinada atividade. A advocacia, por seu turno, é orientada por um número extremado de princípios, justapostos em Estatuto, Código de Ética e na própria Constituição Federal: princípio da imprescindibilidade do advogado para administração da justiça, da capacidade postulatória exclusiva, do sigilo profissional e tantos outros.

Nesse diapasão, os princípios a seguir elencados possuem caráter ontológico, na medida em que se confundem com o próprio sentido de existência da profissão, razão por que a ofensa a qualquer deles representa sério risco aos bens protegidos pelo sistema. Entre outros, são princípios fundamentais da praticagem:

\subsection{Princípio da Sinistralidade Mínima}

Este princípio é sem dúvida o mais relevante da atividade de praticagem. Todos os demais princípios a esse se posicionam em condição de dependência. A busca da sinistralidade mínima é a razão de ser do prático. Se de um lado o princípio reconhece a impossibilidade de eliminação total dos sinistros, de outro, aponta para a realidade possível de se alcançar índices mínimos de acidentes, por meio de trabalho eficiente e eficaz. Avança-se.

O prático presta seu serviço colocando à disposição do comandante sua expertise. Sua presença a bordo resulta em externalidades positivas que beneficiam a sociedade e operam a favor do meio ambiente. Praias limpas, pescadores satisfeitos, tráfego do porto sem solução de continuidade, jornalistas sem tragédias ecológicas para contar, são alguns dos sinais silenciosos dessa profissão.

Entretanto, por via inversa, externalidades negativas poderão ocorrer traduzidas em danos a vários setores da economia. Um acidente marítimo, muitas vezes, vem acompanhado de prejuízos ao meio ambiente, à comunidade de pescadores, aos habitantes 
do entorno, aos que frequentam as praias, aos que vivem da navegação, ao patrimônio público e privado e, sobretudo, aos tripulantes das embarcaçóes.

Por conseguinte, a possibilidade de essas externalidades negativas ocorrerem é a principal razão para que os serviços de praticagem sejam regulados tecnicamente, na busca de índices mínimos de sinistralidade. $\mathrm{Na}$ esfera do meio ambiente, por exemplo, é dever do Estado a proteção desses direitos difusos, a ponto de terem sido alteados a status constitucional:

Art. 225 Todos têm direito ao meio ambiente ecologicamente equilibrado, bem de uso comum do povo e essencial à sadia qualidade de vida, impondo-se ao Poder Público e à coletividade o dever de defendê-lo e preservá-lo para as presentes e futuras geraçôes (BRASIL, 1988).

Em boa exegese, o texto da Carta Política incumbe ao Poder Público, entre outros, o dever de regular tecnicamente os serviços de praticagem para que sejam apoucadas as possibilidades de externalidades negativas e à sociedade o dever de fiscalizar quando o Estado, por razóes tantas, não cumprir o seu papel de bom regulador.

Em sintonia com essa linha de pensamento, a IMO reconheceu a importância dos práticos na promoção da segurança da navegação e na proteção do meio ambiente marinho. Recomendando aos governos dos Estados-membros a adoção de sistemas de praticagem seguros e eficientes, obviamente, no desejo de se elidir ou mitigar as externalidades negativas. Verbis:

Recognizing that maritime pilots play an important role in promoting maritime safety and protecting the marine environment [...]. Governments should encourage the establishment or maintenance of competent pilotage authorities to administer safe and effcient pilotage systems. ${ }^{2}$ (IMO, 2003, Preâmbulo e Anexo 1, item 1.3).

Insta gizar que o princípio da sinistralidade mínima aponta para dois vetores distintos, a saber: a obrigatoriedade do serviço e a formação do prático. Ora, não haverá sistema seguro e eficiente se os práticos não possuírem expertise adequada. Tampouco, de nada adianta um serviço altamente especializado, seguro e eficiente, se ele não for usado pelos navegantes.

Em cumprimento às recomendaçôes da IMO, a quase totalidade dos países-membros positivaram ou mantiveram em suas legislações o serviço de praticagem compulsório e adequaram seus requisitos de formação de práticos aos paradigmas da Organização.

2 Reconhecendo que os práticos desempenham um papel importante na promoção da segurança da navegação e na proteção do ambiente marinho [...]. Os governos devem incentivar a criação ou a manutenção de autoridades competentes para administrar sistemas de praticagem seguros e eficientes (tradução nossa). 
No que se refere à formação e à expertise do prático, a IMO adotou uma série de recomendaçóes, sendo uma delas a necessidade de o profissional manter-se atualizado, ostentando proficiência continuada, devendo comprová-la a intervalos periódicos. Eis excerto pertinente da Resolução:

In order to ensure the continued proficiency of pilots and updating of their knowledge, the competent pilotage authority should itself, at intervals not exceeding five years, that all pilots under its jurisdiction continue to possess recent navigational knowledge of local area to which the certificate of license applies. ${ }^{3}$ (IMO, 2003, Anexo 1, item 6.1.1).

Essa necessidade de proficiência continuada não constava da legislação brasileira, tampouco fazia parte das normas regulamentadoras da Autoridade Marítima. Para atender a essas recomendaçóes, a Diretoria de Portos e Costas alterou a NORMAM-12, criando a obrigatoriedade de os práticos frequentarem cursos de atualização, nos seguintes termos:

0250 - ATUALIZAÇÃO DOS PRÁTICOS. a) A atualização do prático consiste na realização do curso de atualização para práticos (ATPR), aprovado pela DPC para atender à Resoluçáo A.960 (23) da Organização Marítima Internacional. b) O prático deve cursar o ATPR a cada ciclo de cinco anos, contados a partir de sua criação em janeiro de 2005 [...]. d) No final de cada ciclo de cinco anos, o prático que não realizou o ATPR fica impedido de concorrer à escala de rodízio única de prático, sendo afastado temporariamente da atividade, até que seja aprovado no curso (BRASIL, 2011).

Em tempos anteriores à Resolução que se analisa, infelizmente, o governo do Alaska, cedendo a pressóes econômicas, tornou a praticagem, para a aproximação do porto de Valdez, facultativa. Essa decisão foi tomada meses antes do maior acidente marítimo da história dos Estados Unidos até aquela data.

No dia 24 de março de 1989 o petroleiro Exxon Valdez derramou no estreito de Prince William mais de 40 milhôes de litros de óleo, que se espalharam por dois mil quilômetros da costa. $\mathrm{O}$ acidente causou uma destruição jamais vista, acarretando a morte de centenas de milhares de aves marinhas, focas e lontras.

Os esforços para o recolhimento e limpeza das áreas afetadas duraram três anos e mobilizaram cerca de onze mil pessoas. Contudo, os danos ambientais ainda são sentidos nos dias atuais e algumas ações judiciais permanecem aguardando decisão final.

3 A fim de garantir a manutenção da proficiência continuada dos práticos e a atualização dos seus conhecimentos, a autoridade competente deve certificar-se, em intervalos não superiores a cinco anos, que todos os práticos sob sua jurisdição continuam a possuir experiência recente de navegação para o local onde os seus certificados de licença se aplicam (tradução nossa). 
A empresa proprietária do navio (ExxonMobil), conforme amplamente divulgado pela mídia, gastou mais de dois bilhóes de dólares, para limpeza das praias, 300 milhóes em indenizaçôes para pescadores e habitantes locais prejudicados e 900 milhóes em processos penais movidos pelos governos dos Estados Unidos e do Alaska. Finalmente, em uma ação civil coletiva com mais de 30 mil vítimas, que demandava cinco bilhóes de dólares, a Suprema Corte americana fixou a indenização em 500 milhóes de dólares.

Logo após o acidente, as autoridades do Alaska perceberam a desastrosa decisão de permitir a navegação do local sem o assessoramento do prático. Imediatamente, alteraram as normas para tornar, como era antes, a praticagem compulsória. Infelizmente, o adágio popular se cumpriu: a tranca foi posta após a incursão do ladrão.

\subsection{Princípio da Independência Funcional}

Há determinadas funçôes em que a decisão tomada pelo profissional à frente do caso deve ser respeitada pelas autoridades a ele vinculadas, sob pena de violação do princípio da independência funcional. Exemplo desse princípio pode ser colhido no direito processual penal. É como se demonstra.

Consoante o artigo 28 do Código de Processo Penal brasileiro, na hipótese de o promotor requerer o arquivamento do inquérito policial, e de o juiz considerar improcedentes suas razóes, o magistrado fará remessa da peça ao procurador-geral e este oferecerá a denúncia, designará outro órgão para oferecê-la ou insistirá no pedido de arquivamento. Nessa última hipótese, estará o juiz obrigado a arquivar o processo.

Percebe-se que o procurador-geral, em respeito ao princípio da independência funcional, não obriga o promotor que requereu o arquivamento à retratação. Em precisa pena, Tourinho Filho (2004) alerta para o fato de o procurador não poder designar o mesmo promotor para efetivar a denúncia, vez que a retratação compulsória seria o mesmo que violentar a consciência jurídica do promotor de justiça.

No serviço de praticagem a violação a esse princípio pode trazer consequências graves, como a ocorrida com o petroleiro Sea Empress, em fevereiro de 1996, quando o prático local foi obrigado, pelas autoridades britânicas, a entrar com o navio, mesmo tendo alertado para o fato de excesso de calado e da necessidade de se aguardar a preamar.

O acidente ocorreu na entrada do porto de Milford Haven, no condado de Pembrokeshire, no País de Gales (Reino Unido). O navio encalhou após colidir com rochas submersas, rasgando o fundo e derramando 72 mil toneladas de óleo no mar. Permaneceu encalhado no canal de acesso ao porto por sete dias, impedindo a movimentação de outras embarcaçóes, gerando prejuízos outros, atingindo vários setores da economia. 
A poluição trouxe sérias consequências à fauna e à flora marinhas, na medida em que ocorreu na regiáo do Parque Nacional de Pembrokeshire, conhecido reduto de animais selvagens da Europa. A área, de preservação ambiental, foi fortemente afetada, em razão de ser também região de grande comércio turístico.

Os pescadores ficaram um ano sem poder voltar às suas atividades, tempo que durou a limpeza da área afetada. Quando eles finalmente regressaram, contabilizaram grandes prejuízos, já que as vendas caíram substancialmente em razão de receio dos consumidores quanto à qualidade dos peixes.

Foram gastos 120 milhôes de libras esterlinas com as operaçóes de limpeza. E, em razão da complexidade, não foram determinados os prejuízos indiretos que a sociedade local teve de suportar.

Três anos após o acidente, os jornais da Europa anunciaram que a autoridade portuária de Milford Haven assumiu a responsabilidade pelo ocorrido, para se beneficiar do instituto da confissão no processo. Admitiu ter obrigado o prático a executar manobra que ele entendia de risco inaceitável. A responsável foi condenada em quatro milhóes de libras esterlinas, além de 825 mil de custas judiciais.

Percebendo a importância do princípio da independência funcional, a IMO, após estudar esse e outros tantos acidentes marítimos similares, por meio da resolução que se analisa, emitiu a seguinte recomendação aos países-membros:

The ASSEMBLY, RECALLING Article 15 (j) of the Convention on the International Maritime Organization concerning the functions of the assembly in relation to regulations and guidelines concerning maritime safety and prevention and control of marine pollution from ships, [...] ADOPTS the following recommendations: [...] The pilot should have the right to refuse pilotage when the ship to be piloted poses a danger to the safety of navigation or to the environment. ${ }^{4}$ (IMO, 2003, Preâmbulo; Anexo 2, item 8).

Permita-se transportar, para efeito didático, os ensinos do magistério de Tourinho Filho para o direito marítimo. Obrigar o prático a executar uma manobra, que ele julgue de risco inaceitável para os bens a serem protegidos, seria violentar a "consciência náutica" desse profissional. Daí a acertada decisão da IMO em garantir o direito de o prático recusar navegação ou manobra que sua consciência profissional reprovar.

4 A ASSEMBLEIA, relembrando o artigo 15 (j) da Convenção sobre a Organização Marítima Internacional, no que diz respeito às atribuiçôes da assembleia, em relação aos regulamentos e diretrizes quanto à segurança da navegação e à prevenção e controle da poluição marinha causada por navios, [...] APROVA as seguintes recomendaçóes: [...] o prático deve ter o direito de recusar a manobra quando o navio a ser praticado colocar em risco a segurança da navegaçáo ou o meio ambiente (traduçáo nossa). 
Nesse aspecto, a legislação brasileira, ainda carece de regulamentação adequada para se harmonizar com o recomendado pela IMO. Na verdade, o texto legal brasileiro aponta para o sentido oposto ao da recomendaçáo. O Decreto no 2.596/98, que regulamenta a Lei Especial, se fez silente e a NORMAM-12 não esclareceu o quanto devia. É como se demonstra:

Lei de Segurança do tráfego Aquaviário (LESTA) - Art. 15 - O prático não pode recusar-se à prestação do serviço de praticagem, sob pena de suspensão do certificado de habilitação ou, em caso de reincidência, cancelamento deste (BRASIL, 1997).

NORMAM-12 - 0231 - CONDIÇÓES DESFAVORÁVEIS - O Prático deverá comunicar, imediatamente, à CP/DL/AG qualquer fato ou ocorrência que implique em risco à segurança do tráfego aquaviário, à salvaguarda da vida humana, à preservação do meio ambiente ou à faina de praticagem na ZP, tais como: a) Condiçôes meteorológicas e estado do mar adversos; b) Acidentes ou fatos da navegação; ou c) Deficiências técnicas do navio ou da tripulaçáo. Essas informaçóes subsidiarão o $\mathrm{CP} /$ DL/AG a declarar a impraticabilidade na ZP, autorizar que o Serviço de Praticagem deixe de ser prestado, ou impedir a entrada e saída de embarcaçôes (BRASIL, 2011).

Percebe-se que o texto da LESTA não admite exceçóes, requerendo interpretação teleológica. Ora, punição tão grave como a perda do direito de exercer a profissão deve pressupor atitude reprochável ao extremo. Assim, quis o legislador, com o verbo "recusar", apontar para comportamento contrário à ética.

Entretanto, há situaçóes em que a recusa se dá, justamente, pela consciência náutica do prático a vislumbrar situação de risco aos direitos difusos, que de ofício, tem o dever de proteger. Portanto, entende esse autor que o dispositivo da LESTA deveria ter sido regulamentado pelo RLESTA, o que, infelizmente, não aconteceu.

$\mathrm{Na}$ tentativa de atender ao clamor da classe profissional, que por várias vezes apontou a desarmonia do dispositivo legal em relação à Resolução A-960 (23) da IMO, a Autoridade Marítima tem tentado, com textos anteriores, e, por fim, com o explicitado anteriormente, criar a possibilidade de uma manobra não ocorrer quando o prático entender ser ela de risco inaceitável.

Ainda assim, com o atual texto, permanece o risco de a autoridade não aceitar os fundamentos do prático e obrigá-lo à realização da manobra. Tal fato coloca o Brasil nas mesmas condiçóes em que estava o Reino Unido, quando do desastre do petroleiro Sea Empress, já mencionado. Daí, a insistência deste autor, na revisão da NORMAM-12, para deixar claro que é um direito do prático a recusa nas condiçóes estabelecidas pela IMO. 
A título de sugestão, esperam-se uma alteração do RLESTA para regulamentar o dispositivo legal pertinente e a imediata substituição do texto da NORMAM-12, no sentido de se respeitar o princípio da independência funcional. Transportando o legado do direito processual penal para o direito marítimo e em respeito à consciência náutica do prático, sugere-se a seguinte redação para o texto normativo:

NORMAM-12 - CONDIÇÓES DESFAVORÁVEIS - Nas hipóteses de condiçôes meteorológicas desfavoráveis ou de questôes técnicas impeditivas para navegação ou manobra seguras, o prático tem o direito de recusar a prestação do serviço, quando convencido de que tais circunstâncias colocam em risco os bens que, por dever de ofício, deve proteger. $\mathrm{O}$ fato deve ser comunicado imediatamente à autoridade marítima que, analisando a situação, deverá: a) de plano, se convencida, autorizar a não prestação do serviço; b) se não convencida, consultar o representante único do serviço de praticagem (RUSP); c) autorizar a manobra a ser realizada pelo RUSP ou outro prático por ele indicado ou d) cancelar definitivamente a navegação ou manobra naquelas condições, se nesse sentido for o pronunciamento do RUSP.

\subsection{Princípio da Manutenção da Experiência Recente}

As atualizaçóes de conhecimentos, de notória sabença, são exigências de qualquer profissão. Médicos, engenheiros, advogados, sociólogos, cientistas políticos e tantos outros, necessitam de estudos e participações em congressos constantes, visando à obtenção de informações das novas tendências, novas descobertas etc. No entanto, na atividade de praticagem, tais exigências ganham um contorno especial, estando positivadas em diversos ordenamentos jurídicos.

O prático deve manter-se familiarizado com as peculiaridades de sua zona de praticagem. Não se trata de simples atualizaçóes ou participaçóes em congressos, mas de uma intimidade que, se faltante, pode ser fator determinante ou contribuinte para acidentes marítimos.

Os termos "familiaridade" e "experiência recente" foram os escolhidos pela IMO (2003, anexo I, inciso 6.3) para explicar a necessidade de manutenção da expertise do prático. Eis a recomendação expressa na Resolução A-960 (23): "Where a pilot in cases of absence from duty, for whatever reason, is lacking recent experience in the pilotage area, the competent pilotage authority should satisfy itself that the pilot regains familiarity with the area on his or her return to duty"s.

5 "Sempre que um prático, nos casos de ausência da escala de serviço, por qualquer motivo, estiver perdendo sua experiência recente na zona de praticagem, a autoridade competente deve certificar-se de 
Nessa cadência, quis a Organização Internacional definir que a expertise exigida de um prático vai além daquelas esperadas dos demais profissionais. A familiaridade com a navegação em águas restritas depende de "experiência recente". Na hipótese de afastamento, normalmente para tratamento de saúde, o prático deve passar por professional updating ${ }^{6}$, antes de seu retorno à escala de serviço.

Não basta ao prático, ou ao comandante na hipótese de isenção da obrigatoriedade de uso do serviço, ser experiente. Importa, além do tempo em que exerce a profissão, a manutenção da experiência recente. Ou seja, a experiência deve unir-se a familiaridade do dia a dia.

A Lei Especial brasileira, regulamentada pela norma menor, no mesmo sentido da recomendação da IMO, determina a execução de um número mínimo de manobras a cada período, sem o qual perde o prático sua habilitação, necessitando recuperá-la antes de seu retorno à escala de serviço:

LESTA - A manutenção da habilitação do prático depende do cumprimento da frequência mínima de manobras estabelecida pela autoridade marítima (BRASIL, 1997).

NORMAM-12 - A recuperação da habilitação é condicionada ao cumprimento de um plano de recuperação de habilitação que considerará o período em que o prático tiver deixado de cumprir o plano de manutenção da habilitação (BRASIL, 2011).

É comum em vários ordenamentos jurídicos a faculdade de usar ou não os serviços de praticagem, em determinados portos para certas embarcaçóes, cujos comandantes comprovem frequência considerável no porto e a devida familiaridade com as peculiaridades locais. Tais exigências devem ser rigorosamente avaliadas pelas autoridades locais, sob pena de violação do princípio que se analisa.

Infelizmente, as pressóes econômicas, exercidas por armadores irresponsáveis, perante as autoridades competentes, têm alargado demasiadamente essas possibilidades de isenção, em desrespeito ao princípio da experiência recente. Exemplar é o caso do navio de passageiros Costa Concordia:

Navegando em águas territoriais italianas e ostentando a bandeira da Itália, o Costa Concordia era comandando por um legítimo italiano, o capitão Francesco Schettino. Italianos também eram os oficiais navegadores. Em razão dessas circunstâncias a legislação local dava ao navio o direito de navegar, mesmo bem próximo à costa, sem o assessoramento de um prático.

que esse prático recuperou a familiaridade com a sua área antes de seu regresso ao serviço”. (tradução nossa)

6 Atualização profissional. (tradução nossa) 
Ocorre que o comandante e seus oficiais navegadores, apesar de suas largas experiências, não mantinham a desejada familiaridade, que só se adquire com a experiência recente, das particularidades do entorno da ilha de Giglio. Como navio de turismo, navegava o Costa Concordia, não só por portos da Europa, mas também da América do Sul. A passagem por essa ilha repetia-se a intervalos muito longos, afastando do comandante e de seus oficiais a experiência especial, recomendada pela IMO.

Em sua última viagem, antes do acidente, o transatlântico partiu do porto de Savona e passou pelas cidades de Marselha, Barcelona, Palma de Maiorca, Cagliari, Palermo e Civitavecchia. Desta última, navegava para o porto de origem do cruzeiro, quando colidiu, em janeiro de 2012, com rochas submersas, nas proximidades da ilha de Giglio, na regiáo da Toscana. Infelizmente, trinta e duas pessoas morreram.

Como não é objetivo desta pesquisa tratar das responsabilidades dos sujeitos da navegação envolvidos nesse acidente, atenta-se tão só para o reconhecimento das autoridades italianas da necessidade de alteração na legislação de praticagem.

Após o acidente, a praticagem na Itália passou a ser compulsória para qualquer navio, independentemente de sua nacionalidade, quando navegarem a menos de quatro milhas da costa. A Itália reconheceu tarde demais o seu dever de cumprir as recomendaçóes da IMO. Desnecessária a analogia com o adágio popular já mencionado anteriormente.

O Brasil encontra-se nas mesmas condiçôes da Itália, antes do acidente mencionado, por violar o princípio da experiência recente de forma indireta. Explica-se de forma mais detalhada essa violação no próximo item.

\subsection{Princípio do Número Limitado}

Ressalva-se que os dois próximos princípios a serem comentados estáo intimamente ligados ao princípio da experiência recente, analisado no item anterior. Não há como se manter a familiaridade com as particularidades locais se não houver um número limitado de práticos para cada região e uma escala de serviços que faça uma divisão equânime do trabalho. Analisa-se essa afirmação.

Nessa sonoridade, o princípio do número limitado obedece à mesma cadência lógica de importância da familiaridade, como condição para manutenção da expertise. Acrescenta-se, ainda, a possibilidade de o trabalho ocorrer sob fadiga, quando o número de práticos para uma determinada região estiver aquém da necessidade.

O princípio, que ora se expóe, aponta para o respeito ao binômio: fadiga versus expertise. Vale dizer que um número elevado de práticos em determinada zona de praticagem diminui, não só a expertise, como também, e principalmente, a experiência recente. 
De outra mão, um número reduzido de profissionais traria excesso de trabalho, podendo comprometer o repouso necessário, expondo o prático à fadiga.

Se a resolução sob comento trata da experiência recente, como já indicado, por outro lado, também se preocupa com a possibilidade de fadiga, recomendando repouso que permita um atuar sob condiçóes de descanso e alerta adequados: "Pilots should be adequately rested and mentally alert in order to provide undivided attention to pilotage duties for the duration of the passage $e^{7}$." (IMO, 2003, anexo 2, inciso 9).

Se tanto a falta da experiência recente como o trabalho sob fadiga são fatores determinantes ou contribuintes de acidentes marítimos, cabe à autoridade responsável determinar o número ideal de profissionais para cada zona de praticagem de tal ordem que evite a fadiga e mantenha a experiência recente.

Em respeito ao princípio que se analisa, o ordenamento jurídico brasileiro concede poderes a Autoridade Marítima para estabelecer o número necessário de práticos e a forma de manutenção da experiência recente, nos seguintes termos:

LESTA - art. $13, \$ 2^{\circ}$. A manutenção da habilitação do prático depende do cumprimento da frequência mínima de manobras estabelecida pela autoridade marítima. Art. $14, \$$ único, I. Para assegurar o disposto no caput deste artigo, a autoridade marítima poderá estabelecer o número de práticos necessário para cada zona de praticagem (BRASIL, 1997).

Regulamentando os dispositivos legais mencionados, em razão do silêncio do RLESTA, a Diretoria de Portos e Costas (DPC), por meio da NORMAM-12, e para atender às recomendaçóes da IMO, no que toca ao princípio da experiência recente, estabeleceu método lógico para determinação do número necessário de práticos por zona de praticagem (ZP).

0245 - NÚMERO DE PRÁTICOS POR ZP. a) A DPC estabelecerá a lotaçáo de práticos por $\mathrm{ZP}$, considerando, dentre outros aspectos, o volume do tráfego de embarcaçóes, o tempo despendido e o grau de dificuldade para a realização das fainas de praticagem, a necessidade de manutenção da habilitaçáo e a carga máxima de trabalho do prático, de acordo com o que estabelece a legislação trabalhista. b) Sempre que julgar necessário, a DPC elaborará estudos para corrigir eventuais distorçôes nas lotaçôes, visando adequá-las às necessidades do serviço de praticagem (grifo nosso). (BRASIL, 2011).

7 Os práticos devem estar adequadamente descansados e atentos, a fim de prestar total atenção ao serviço de praticagem, durante todo o plano de navegação e manobra. (tradução nossa) 
Dessa forma, caminhava a Autoridade Marítima, em harmonia com as recomendaçóes da IMO, com pequenos desvios, até que, ao que tudo indica, a contragosto, teve que vilipendiar seus próprios conceitos e desrespeitar norma, por ela mesma produzida, para atender a desastrosa intervenção do Governo, no apagar das luzes de 2012.

Essa ordem intervencionista de alterar o número de práticos para mais, sem os critérios normativos, foi o prenúncio para o Decreto no 7.860/12 que pretende modificar substancialmente a regulação técnica e econômica da praticagem brasileira.

Nesse passo, a Autoridade Marítima determinou um aumento na ordem de cinquenta por cento da lotação dos práticos em todas as zonas de praticagem, alterando a NORMAM-12, ao arrepio dos critérios estabelecidos na própria norma.

Os quatrocentos práticos existentes passaram a seiscentos, em um único concurso, sendo que um certame anterior já havia trazido ao mercado um pouco mais de cem profissionais. Há situaçôes, como a da praticagem do Rio de Janeiro e da de Santos, que o número de práticos novos, e ainda em processo de aprendizagem e aquisição de experiência, supera o número dos mais antigos. Tal situação é preocupante por três motivos, a saber:

Primeiro, os práticos que entraram, em razão desse concurso, perfazem um número nunca concebido na história da praticagem brasileira. Como formá-los, no tempo pré-estabelecido, se suas formaçóes dependem de manobras a serem realizadas a bordo de navios e se o número destes não se alterou?

Multiplicando-se a quantidade de manobras exigidas para formação de um prático pelo número de profissionais a serem formados, tem-se que o resultado é maior do que a quantidade de navios disponíveis. O aprendizado cuidadoso, realizado de forma individual, está sendo feito em grupos, ou seja, vários praticantes em uma única manobra.

Desse modo, a qualidade do ensino torna-se apoucada, já que um único prático instrutor tem de dividir sua atenção com mais de um aprendiz. Em consectário lógico, há de esperar-se que a formação desses novos profissionais, de igual modo, não estará nos padróes de qualidade estabelecidos pela IMO.

Segundo, se a quantidade de práticos novos, e ainda em processo de aquisição de experiência, é maior do que a dos mais experientes, segue-se que os praticantes serão treinados e formados por práticos não aptos para transferir experiência. Se a qualidade do ensino já estava prejudicada pela impossibilidade de treinamento individual, agrava-se pela inaptidão momentânea dos monitores.

Terceiro, após a formação desses novos práticos, o que já acontece em alguns portos, há e haverá uma quantidade exagerada de profissionais para um número constante de navios, fazendo com que a escala de serviço seja demasiadamente alargada, comprometendo seriamente a manutenção da experiência recente estabelecida pela IMO. 


\subsection{Princípio da Divisão Equânime}

Como dito anteriormente, esse princípio prevê uma divisão equilibrada do serviço, para que todos os práticos de uma mesma ZP possam manter suas habilitaçôes e, em conformidade com os parâmetros da IMO, manter a experiência recente.

De pouco adiantaria o estabelecimento de um número determinado de práticos se as manobras fossem direcionadas de forma a privilegiar alguns práticos em detrimento de outros. Em pouco tempo, alguns práticos perderiam suas habilitaçôes.

De toda sorte, a obediência a esse princípio só será eficaz se houver também obediência ao princípio do número limitado. Por mais que se faça uma divisão equânime, se o número de práticos for excessivo, todos manobrarão em número insuficiente para a manutenção da familiaridade recomendada pela IMO.

Em outras palavras, embora esse princípio esteja sendo observado pelas autoridades brasileiras, por meio de uma escala única entre os profissionais, com distribuição equilibrada do serviço, seu objetivo está frustrado em razão da violação do princípio anterior.

\section{Governança Vilipendiada}

O Brasil, em razão de sua posição internacional e de seu interesse nas questóes envolvendo o comércio marítimo, é membro da Organização Marítima Internacional e perante essa organização mantém seu órgão representativo: a Representação Permanente do Brasil junto a IMO (RPB-IMO), com sede em Londres, ali estrategicamente fixada, na mesma cidade-sede da IMO.

Considerando a necessidade de internalizaçáo das normas regulamentadoras para o transporte marítimo internacional adotadas pela IMO, a estrutura governamental brasileira conta, ainda, com a Comissão Coordenadora dos Assuntos da Organização Marítima Internacional (CCA-IMO), com sede em Brasília.

Ademais, a CCA-IMO é apoiada técnica e administrativamente pela Secretaria Executiva da Comissão Coordenadora dos Assuntos da Organização Marítima Internacional (SEC-IMO), que ocupa as instalaçóes da Diretoria de Portos e Costas (DPC) no Rio de Janeiro. Portanto, três órgãos brasileiros são responsáveis pela atuação e representação dos interesses brasileiros na IMO, movimentando mais de uma centena de funcionários, no Brasil e no exterior.

Como é de conhecimento notório, a IMO conta atualmente com 171 Estadosmembros e três associados (Hong Kong, Macau e Ilhas Faroe), além de uma quantidade extremada de organizaçóes não-governamentais que exerce papel consultivo. A Organização é composta pela Assembleia, pelo Conselho, pelo Secretariado e por cinco Comitês. 
O Conselho é o órgão executivo da IMO. É formado por 40 países eleitos pela Assembleia para mandatos de dois anos. O Brasil por vários anos tem ocupado papel de destaque, tendo assento em uma das cadeiras do Conselho, sendo essa sua posição atual, vez que foi reconduzido para o biênio de 2014/2015.

Além de aprovar mais de 60 tratados importantes, a IMO trabalha exercendo governança global, contando com a cooperação de seus membros para preservação da segurança da navegação e do meio ambiente marinho. Para isso, adota e renova uma série de resoluçóes.

Depois de amplamente discutidas nos diversos subcomitês, e sendo aprovados os textos finais nos comitês pertinentes, com a participação de todos os Estados-membros, as resoluçôes são adotadas na Assembleia por unanimidade. Essa praxe da IMO prende-se ao fato de que suas recomendaçóes externadas nas resoluçóes, ainda que soft law, são fruto de decisão consensual em cooperação internacional, não se esperando nenhuma rejeição posterior.

Para alguns autores essa praxe da IMO náo se faz mais necessária, vez que o modelo da soft law tem alcançado espaço cada vez maior no direito internacional e no âmbito de aceitaçáo dos Estados. Mario Giovanoli (2000) assevera que na esfera do comércio internacional a preferência pela soft law se justifica em razáo das constantes mudanças nas regras, em respeito às características das relaçóes financeiras transfronteiriças, sendo a maioria das normas desse tipo de caráter não vinculativo e nem por isso, menos cogente.

Em consonância com o magistério de Mario Giovanoli está a doutrina de Nguyên Quoc Dinh (1999). Para esse jurista francês, a falta de obrigatoriedade das recomendaçóes contidas nas resoluções internacionais não significa que estas não tenham alcance jurídico. Ao revés, seu impacto político é muitas vezes fundamental e justifica a obstinação com que os Estados participam nos debates que precedem a adoção desses instrumentos normativos.

De igual modo, a segurança da navegação e a proteção do meio ambiente marinho exigem normas flexíveis e de fácil alteração, na medida em que necessitam de atualizaçóes constantes e imprescindíveis para manterem-se o alto padrão de qualidade e de controle necessários, muitas vezes, incompatíveis com a rigidez dos tratados. Nessa toada, os Estados têm aceitado a governança capitaneada pela da IMO.

Desde o final do século passado, o mundo não tem mais dúvidas sobre a importância de açóes coordenadas e da necessidade de cooperação entre os Estados, sendo que o progresso depende de regulação internacional que só pode ser estabelecida por mecanismos de consenso democrático. Como ensina Alcindo Gonçalves (2011), só a governança global é capaz de lidar com os riscos sistêmicos que não têm limites geográficos, mas que inexoravelmente trazem efeitos generalizados sobre todos os países. 
Desse modo, ao descumprir a Resolução A-960 (23), o Brasil tem ultrajado essa governança global, em atitude reprochável e incoerente com a liderança que exerce no âmbito da Organização e de seu Conselho. Ainda, essa posição assumida é absolutamente abstrusa, se posta em paralelo com os gastos do Brasil para manutenção de órgãos especiais, tanto em solo brasileiro quanto no exterior.

Ao que parece, os assessores jurídicos dos executivos que representam o Brasil na IMO não estão dando conta de explicar as liçôes de Norberto Bobbio (2007), a respeito da real função do direito. Para esse doutrinador italiano, nossas preocupaçóes não devem estar postas para saber "como o direito é feito", mas, na descoberta de "para que o direito serve”.

Não há dúvidas de que o Brasil dará trabalho extra aos seus diplomatas para explicar às autoridades da IMO porque trabalhou tanto na aprovação de uma resolução, porque exerceu seu papel de liderança no Conselho e porque votou na sua aprovação, se pretendia, ao depois, produzir decreto presidencial que vilipendia os princípios insertos nessas recomendaçóes de segurança.

\section{Conclusões}

Restou demonstrado que algumas recomendaçóes da IMO, expressas na Resoluçáo A-960 (23), que não constavam da legislação especial brasileira, foram introduzidas no ordenamento jurídico por meio da NORMAM-12, em acertada decisão da autoridade marítima brasileira, que sempre teve a exata dimensão da importância da liderança exercida pela IMO na área da segurança marítima.

De outra mão, constatou-se que há princípios importantes nessa Resolução que estão sendo violados pelo Estado brasileiro. Ainda se verificou que essa violação está sendo posta por decreto presidencial, caracterizando-se, assim, em intervencionismo político em área técnica, verdadeiro ultraje à governança global como sugere o título deste artigo.

Considerando-se que o princípio da experiência recente está intimamente ligado ao da sinistralidade mínima e que a violação daquele consubstancia-se em violação também deste, conclui-se que o Brasil está em rota de colisão com quatro dos cinco princípios analisados.

Essas violaçóes colocam em risco os bens protegidos pelo sistema de praticagem, mencionados anteriormente: a segurança da navegação, o meio ambiente, os patrimônios público e privado e as vidas insertas na aventura marítima.

Desse modo, na medida em que os comandantes estrangeiros confiam que essas normas de segurança da IMO são por todos respeitadas, em razão de ser esse o costume 
internacional e a prática da boa governança, essa violação do Brasil tem caráter de fraude internacional, fazendo do Brasil uma rota de perigo para os que operam em seus portos.

Considerando, ainda, que o Brasil não está totalmente sozinho nessas violaçóes, como se viu no caso do acidente do Costa Concordia, estes articulistas vislumbram a possibilidade de os países-membros decidirem por transformar a Resolução A-960 (23) em uma Convenção.

A medida sugerida, poderia fazer com que os Estados-membros, relutantes em adotar as recomendaçóes da IMO, e que ainda não compreenderam a importância da soft law para o setor, tivessem sobre si maior grau de coercitividade. $\mathrm{Na}$ hipótese de descumprimento, responderiam por ilícito internacional. Infelizmente, a coerção ainda é a única linguagem compreendida por aqueles que não se ajustam ao saudável sistema da governança global.

\section{Referências}

BOBBIO, Norberto. Da Estrutura à Funçáo. Novos Estudos de Teoria do Direito. Barueri: Manole, 2007.

BRASIL. Constituiçáo da República Federativa do Brasil, 1988. Disponível em www. planalto.gov.br. Acessado em 10/05/2015.

. Lei no 9.537 de 1997 - Lei de Segurança do Tráfego Aquaviário - LESTA. Disponível em www.planalto.org.br. Acessado em 10/05/2015.

. Decreto no 2.596 de 1998, - RLESTA. Disponível em www.planalto.gov.br. Acessado em 10/05/2015.

. Diretoria de Portos e Costas. NORMAM-12, 2011. Disponível em www.dpc. mar.mil.br. Acessado em 10/05/2015.

. Decreto no 7.860 de 2012. Disponível em www.planalto.gov.br. Acessado em 10/05/2015.

DINH, Quoc; DAILLIER, Patrick; PELLET, Alain. Direito internacional público. Tradução: Vítor Marques Coelho. Lisboa: Fundação Calouste Gulbenkian, 1999.

GIOVANOLI, Mario. A new Architecture for the Global Financial Market Legal: Legal Aspects of International Financial Standard Setting, in GIOVANOLI, Mario (Edit.). International Monetary Law: Issues for the New Millenium, Oxford: Oxford University Press, 2.000 .

GONÇALVES, Alcindo e COSTA, José A. Fontoura. Governança Global e Regimes Internacionais. São Paulo: Almedina, 2011. 
INTERNATIONAL MARITIME ORGANIZATION (IMO). Resolution A-960 (23), 2003. Recommendations on Training and Certification and Operational Procedures for Maritime Pilots other than Deep-sea Pilots, 2003. Disponível em www.imo.org. Acessado em 10/05/2015.

SUNDFELD, Carlos Ari. Fundamento de Direito Público. São Paulo: Malheiros, 1992.

TOURINHO FILHO, F. da Costa. Manual de processo penal. 6a ed. São Paulo: Saraiva, 2004. 